\title{
Corticotropin-Releasing Factor in Olivocerebellar Climbing-Fiber System of Monkey (Saimiri sciureus and Macaca fascicularis): Parasagittal and Regional Organization Visualized by Immunohistochemistry
}

\author{
Choong I. Cha and Stephen L. Foote \\ Department of Psychiatry, School of Medicine, University of California, San Diego, La Jolla, California 92093, and \\ Research Institute of the Scripps Clinic, La Jolla, California 92037
}

An antiserum directed against the human form of corticotropin-releasing factor (CRF) was utilized for immunohistochemical visualization of the distribution of this peptide in the inferior olivary nucleus and cerebellum of 2 monkey species (Saimiri sciureus, Macaca fascicularis). Colchicine pretreatment was not used. In both species, immunoreactivity was evident in the vast majority of neurons in the inferior olivary nucleus, with perikarya in the medial accessory olive exhibiting especially intense staining. In cerebellum, no labeled perikarya were present, but immunoreactive axons exhibiting the morphological characteristics of climbing fibers and their collaterals were observed in cortical and nuclear structures. In the cortex, most labeled axons were confined to the molecular and Purkinje cell layers. In the sagittal plane, individual axonal arbors originated from thick, isolated axons at the base of the molecular layer and repeatedly ramified as they extended toward the cortical surface. In coronal sections, only thin, paired profiles were present. Labeled processes also formed efflorescences in the granular layer of cortex and were evident as highly arborized axons in cerebellar nuclei. In each of these instances, the labeled elements resembled climbing fibers or their collaterals as visualized by other methods. Other labeled processes in the granular layer exhibited the morphological characteristics of mossy fiber axons.

Immunoreactive, climbing-fiber-like axons were present in the molecular layer throughout the major regions of cerebellar cortex. However, the most intensely labeled of these axons were strikingly clustered within particular regions and parasagittal domains. In the vermis and intermediate zone, intensely labeled axons were present only within parasagittal zones similar in location to those defined by climbing fiber innervation from the medial accessory olive. Intensely labeled axons were also densely but uniformly distributed

Received Sept. 21, 1987; revised Mar. 7, 1988; accepted Mar. 14, 1988.

During the course of this work, C. I. Cha was on leave from the School of Medicine, Seoul National University, Seoul, Korea. Antisera were generously provided by $W$. Vale and J. Rivier of the Peptide Biology Laboratory of the Salk Institute. This research was supported by PHS Grant MH40008 and by grants from the Dystonia Medical Research Foundation and the MacArthur Foundation. We wish to thank W. Chee for excellent technical assistance and J. H. Morrison and F. E. Bloom, who provided resources and consultation during these studies.

Correspondence should be addressed to Stephen L. Foote, Department of Psychiatry (M-003), University of California, La Jolla, CA 92093.

Copyright (C) 1988 Society for Neuroscience $0270-6474 / 88 / 114121-17 \$ 02.00 / 0$ within the uvula, the medial region of the dorsal paraflocculus, and the dorsal region of the pyramis, areas that receive their climbing fiber input primarily from the medial accessory olive. Labeled fibers were much less dense and were not clustered in the lateral hemispheres.

The present observation of CRF-like immunoreactivity in the monkey olivocerebellar pathway is compatible with the previous observation of CRF mRNA within olivary neurons of rat, baboon, and human (Young et al., 1986) and with recent immunohistochemical findings in rat (Sakanaka et al., 1987; Palkovits et al., 1987), cat (Cummings et al., 1988; Kitahama et al., 1988), sheep (Cummings et al., 1988), and human (Powers et al., 1987). The present report thus reinforces the suggestion that CRF is contained within the primate olivocerebellar pathway. Furthermore, it indicates that neurons in the medial accessory olive and their climbing fiber projections contain higher levels of CRF than neurons in other olivary subdivisions, producing parasagittally distributed and regionally specialized projections of these CRFrich climbing fibers onto cerebellar cortex.

Corticotropin-releasing factor (CRF) is a 41 -amino acid peptide that is known to act as a hypothalamic releasing factor, stimulating the secretion of adrenocorticotropic hormone and betaendorphin from the anterior pituitary (see Vale et al., 1983, for review). In addition, several lines of evidence (biochemical, histochemical, and electrophysiological) indicate that CRF may function as a neurotransmitter in extrahypophyseal neuronal pathways. For example, there have been several immunohistochemical studies characterizing the anatomic distribution of CRF-like immunoreactivity (CRFLI) in rat brain (Bloom et al., 1982; Merchenthaler et al., 1982; Olschowka, 1982; Cummings et al., 1983; Joseph and Knigge, 1983; Swanson et al., 1983; Fellman et al., 1984; Merchenthaler, 1984; Skofitsch and Jacobowitz, 1985; Sakanaka et al., 1987). These reports have described extensive, widely distributed systems of CRFLI in extrahypophyseal neuronal perikarya and fibers. However, limited information is available concerning the distribution of CRF in primate brain. For example, the only available anatomic observations from monkeys, based on immunohistochemical studies, have been limited to examinations of hypothalamus (Kawata et al., 1982; Paull et al., 1984) and circumventricular organs (Kawata et al., 1983). Also, with one exception described below, similar limitations have applied to immunohistochemical stud- 
ies of human brain. Thus, we have undertaken a series of immunohistochemical studies in order to characterize the anatomic distribution of extrahypophyseal CRFLI in brain stem areas of 2 species of monkey (Macaca fascicularis and Saimiri sciureus) (Cha and Foote, 1987; Foote et al., 1987; Foote and Cha, 1988). An antiserum directed against the human form of CRF, identical to the rat form (Vale et al., 1981; Rivier et al., 1983; Shibihara et al., 1983) has been utilized to visualize CRFLI in neuronal perikarya and fibers.

Recently, certain observations have suggested that CRF is contained in neuronal perikarya in the inferior olive and in the axons projecting from this nucleus into the cerebellum. These axons constitute the olivocerebellar pathway which provides climbing-fiber input throughout cerebellar cortex, as well as collateral innervation of deep cerebellar nuclei. In most early immunohistochemical studies, CRFLI was either not observed in the olivocerebellar system or only weak immunoreactivity was evident (Merchenthaler et al., 1982, 1984; Cummings et al., 1983; Schipper et al., 1983). However, recent light-microscopic observations in rat (Palkovits et al., 1987; Sakanaka et al., 1987), cat (Cummings et al., 1988; Kitahama et al., 1988), and sheep (Cummings et al., 1988) have demonstrated substantial CRFLI in inferior olive perikarya and in axons in cerebellum. This is compatible with reports of high levels of CRF in inferior olive as measured by radioimmunoassay (Palkovits et al., 1983, 1985) and with demonstrations of CRF mRNA in these neurons by in situ hybridization in rat (Young et al., 1986; Palkovits et al., 1987), baboon, and human (Young et al., 1986). One electron-microscopic study has shown CRFLI in axons terminating on rat Purkinje cell dendritic spines (Palkovits et al., 1987), and one immunohistochemical study has reported CRFLI in human olivary neurons and in axons in cerebellar cortex (Powers et al., 1987). Taken together, these observations suggest that CRF may be a neurotransmitter in the olivocerebellar system of at least several species.

In the present study, the distribution of CRFLI in components of the olivocerebellar system was examined at the light-microscopic level in 2 species of monkey (Saimiri sciureus and Macaca fascicularis). In both species, dense immunoreactivity was observed in inferior olive perikarya and in axons with climbingfiber-like morphology in cerebellar cortex and in cerebellar nuclei. These observations are novel in that (1) very intense labeling of CRF-containing cerebellar axons permits the first detailed morphological description of these fibers in primates, (2) a previously unreported preferential distribution of intensely labeled neurons within the medial accessory olive is described, and (3) a striking regional and parasagittal distribution of axons intensely labeled for CRF is demonstrated in cerebellar cortex.

\section{Materials and Methods}

Immunohistochemical material was obtained from 4 adult squirrel monkeys (Saimiri sciureus) and 3 adult cynomolgus monkeys (Macaca fascicularis) using previously published methods (Morrison and Foote, 1986). Briefly, animals were deeply anesthetized with ketamine $(25 \mathrm{mg}$ $\mathrm{kg}$, IM) and sodium pentobarbital $(15 \mathrm{mg} / \mathrm{kg}$, IP). They were then perfused transcardially with ice-cold $1 \%$ paraformaldehyde in phosphate buffer $(0.15 \mathrm{M})$ for $1.0 \mathrm{~min}$ followed by perfusion with ice-cold $4 \%$ paraformaldehyde in phosphate buffer for $9 \mathrm{~min}$ at a flow rate of 250 $500 \mathrm{ml} / \mathrm{min}$ (depending on body size). Macaca monkeys were artificially respirated before and during the initiation of the perfusion, while Saimiri were not. The brain was removed immediately and cut into blocks 3$5 \mathrm{~mm}$ thick. These blocks were immersed in cold fixative for $6 \mathrm{hr}$ and then washed in a series of cold sucrose solutions of increasing concentration. They were then stored in $18 \%$ sucrose in phosphate buffer for
1-7 d. Frozen sections, $40 \mu \mathrm{m}$ thick, were cut and incubated, freely floating, for $48-72 \mathrm{hr}$ in primary antiserum diluted 1:2000. The primary antiserum was visualized using avidin-biotin kits from Vector Labs (Burlingame, CA), which utilize as a sccondary antiscrum biotinylated anti-rabbit IgG that is subsequently bound to biotinylated HRP using an avidin bridge. The sections were developed for peroxidase reactivity with 3,3'-diaminobenzidine. The distribution of CRFLI was evaluated by careful comparison of the immunohistochemical sections with adjacent Nissl-stained sections. The nomenclatures of the atlases of Emmers and Akert (1963) for Saimiri and that of Kusama and Mabuchi (1970) for Macaca were used for brain-stem structures and that of Madigan and Carpenter (1971) for cerebellar structures.

The primary antiserum utilized in these studies was raised in rabbits and was directed against the rat/human form of CRF (Vale et al., 1981; Rivier et al., 1983; Shibihara et al., 1983). It was generously furnished by $W$. Vale and J. Rivier of the Salk Institute. In initial experiments utilizing antisera directed against the ovine form of CRF, immunohistochemical staining was found to be very weak. For the antiserum utilized in these studies (lot c70), a dilution series of 1:1000, 1:2000, and 1:4000 was evaluated, and staining from the 1:2000 dilution was found to be optimal. As controls for nonspecific immunoreactivity, a sample of sections was reacted without primary antiserum, and a different sample was exposed to 1:2000 primary antiserum that had been preadsorbed for $24 \mathrm{hr}$ with human CRF (Penninsula Laboratories, Belmont, CA) at a concentration of $0.1 \mathrm{mg} / \mathrm{ml}\left(2.1 \times 10^{-5} \mathrm{M}\right)$. Sections from these samples did not exhibit any of the immunoreactivity described in this report.

\section{Results}

\section{General observations}

Immunoreactive neuronal perikarya and processes were observed in numerous brain regions. Many similarities with previous descriptions of the distribution of CRFLI in rat brain were evident, although substantial differences were also observed (Foote and Cha, 1988). In the regions examined in the present study, dense CRFLI was observed in inferior olive perikarya and in axons within this nucleus, and labeled axons were observed in cerebellar cortex and cerebellar nuclei. The distributions and densities of labeled perikarya and fibers were very similar in Saimiri and Macaca. However, inferior olive neuronal perikarya and cerebellar axons tended to be more intensely stained in Saimiri than in Macaca. Although interanimal variability in staining intensity was evident, the observations reported here were similar in all animals.

\section{Inferior olive}

The neurons of the inferior olive constituted the largest collection of immunoreactive perikarya observed in the rhombencephalon. It appeared that essentially all of the large neurons within the boundaries of the nucleus were at least moderately immunoreactive (Fig. 1). In immunohistochemical sections counterstained for Nissl substance, only occasional Nissl profiles $(<5 \%)$ did not exhibit unambiguous immunoreactivity. Although perikarya throughout the olivary complex were clearly labeled, the medial accessory olive contained a larger proportion of the most intensely labeled perikarya than did other subdivisions of the complex (Fig. 2). The principal nucleus and the dorsal accessory nucleus both contained a lower, approximately equal proportion of intensely stained perikarya. No consistent clustering of intensely labeled neurons into smaller groups within subdivisions was evident.

Labeled processes with axonal morphology were also evident within and adjacent to the inferior olive (Fig. 2). Although these processes were visible throughout the nucleus, they were most dense in the lateral portion of the medial accessory olive, especially in its caudal extent. 


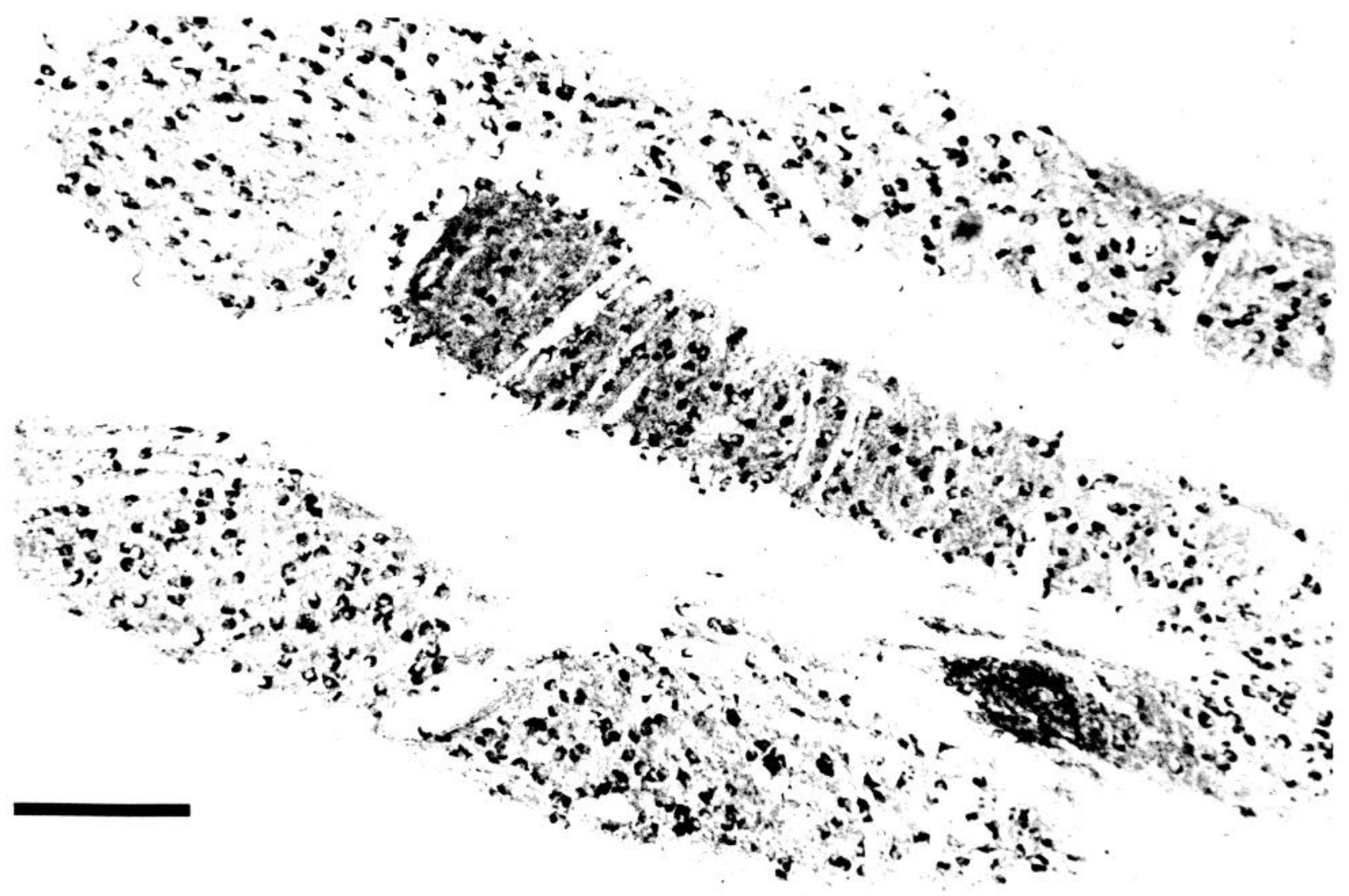

Figure 1. Bright-field photomicrograph of labeled neuronal perikarya in a coronal section through the rostral portion of the inferior olive. Dorsal is up and lateral is to the right. The ventral subdivision, the medial accessory olive, contains the most intensely labeled perikarya, although this is more clearly evident in the central and caudal portions of the nucleus. Scale bar, $200 \mu \mathrm{m}$.

\section{Cerebellum: general observations}

No immunoreactive perikarya were observed in the cerebellum. Labeled axons were evident in numerous regions of the cerebellar cortex and in cerebellar nuclei. The morphology of these axons is described immediately below, and finally the distribution of these axons in various regions of cerebellar cortex is described.

\section{Cerebellar cortex: axon morphology}

The most prominent population of labeled axons in cerebellar cortex was localized within the Purkinje cell and molecular layers (Figs. 3, 4, 6-10) and had the general appearance of climbing fibers. These axons were evident within and adjacent to the Purkinje cell layer as thick, isolated processes that typically bifurcated within the deep portion of the molecular layer and then arborized profusely as they ascended toward the surface of the cerebellum (Fig. 3). They were generally contained within the deepest $80 \%$ of the molecular layer, with only a few branches extending as far as the cerebellar surface. In frontal sections, they appeared as parallel pairs of labeled processes extending across the molecular layer, often within the plane of section (Figs. 4, 10). The processes were of larger caliber in the deep portions of the molecular layer, and often formed thick, ringlike structures in the superficial portion of the Purkinje cell layer.

A much less dense population of immunoreactive processes was observed in the granular layer. These processes were most often evident as efflorescences at various levels between the white matter and the Purkinje cell layer (Figs. 3, 4). Each efflorescence was composed of an extremely compact cluster of axonal varicosities and intervaricose segments, which appeared to arise from an individual labeled axon. Other labeled processes with the appearance of fibers cut in cross section or of small rosettes were also evident in the granular layer. Within and adjacent to the Purkinje cell layer, there were often small-caliber, varicose axons that surrounded Purkinje cell perikarya. Occasional labeled fibers were observed in white matter.

\section{Cerebellar nuclei: axon morphology and distribution}

Dense networks of immunoreactive fibers were also observed in all 3 cerebellar nuclei (Fig. 5). These fine-caliber axons were highly arborized. The fastigial nucleus exhibited a slightly greater density of axons than the interpositus or dentate nuclei.

\section{Cerebellar cortex: axon distribution}

As noted above, labeled axons in cerebellar cortex were most prominent within the molecular layer. For this population, there were striking variations in the intensity of axon labeling and in the clustering of labeled processes in various regions of cerebellar cortex. Certain cortical areas contained dense collections of intensely labeled axons, while other areas contained sparse populations of moderately or lightly labeled axons. The regions of dense innervation were generally confined to the vermis and intermediate zone. For example, the uvula exhibited a uniform, high density of intensely labeled fibers (Fig. 6). The dorsal region of the pyramis (Fig. 6) and the medial region of the dorsal 

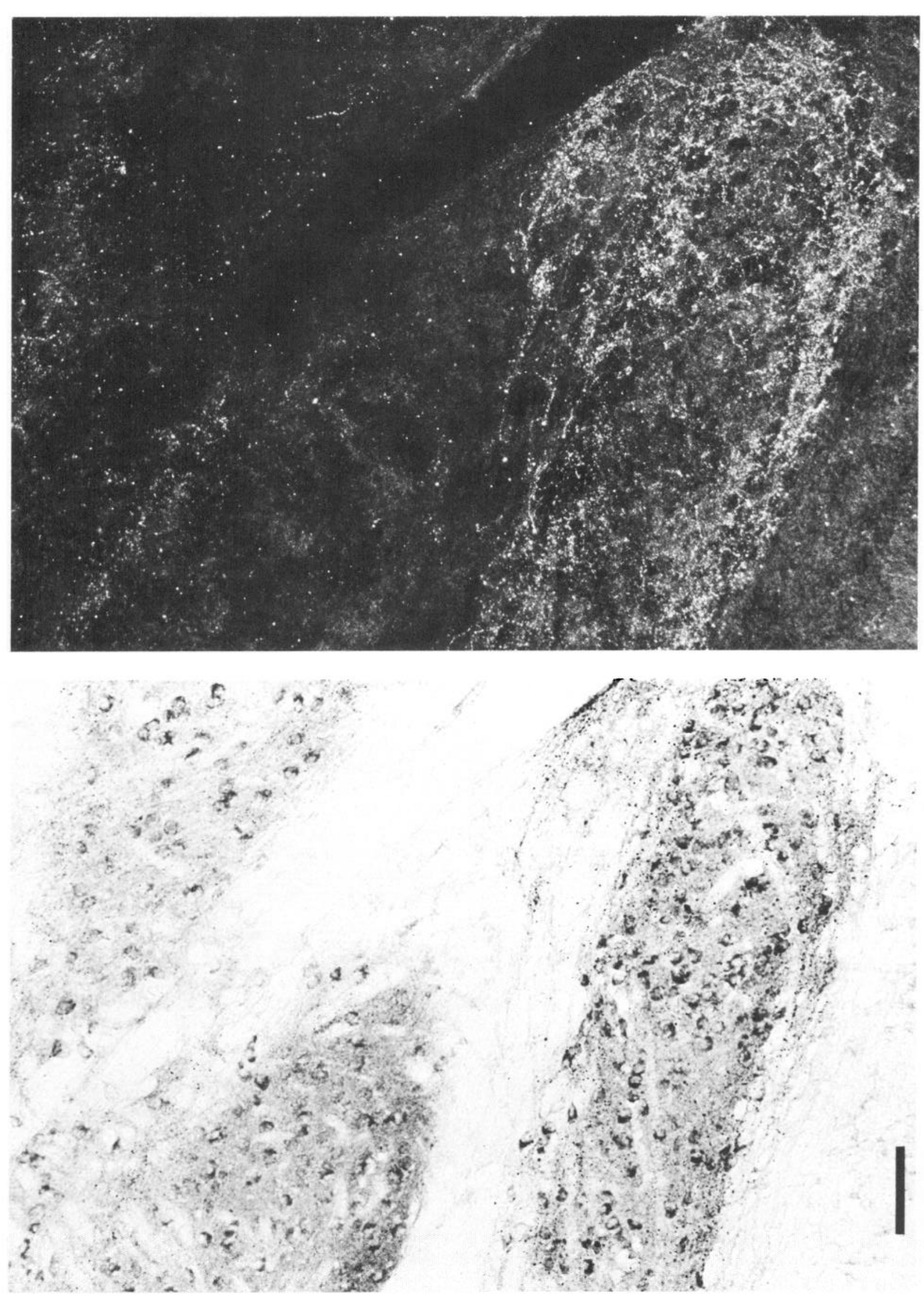

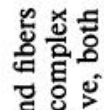

녕

猔

氙兘要

它:

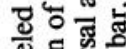

密.

근

$\geqq$

흔 편유을

品实

क जे

目

要政

然

정

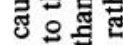

急

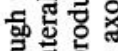

현

호흥도

ธิ

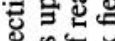

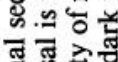

舜

的它

.

웡

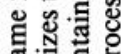

ज菏

政

등.

도워ำ

品.

을뭉롱

혼도

응

동

오월

政

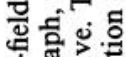

논릉

공형

的

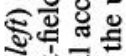

可

要递

도워

․․․․․․․

는휴 웡

웜등

㖓

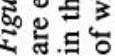



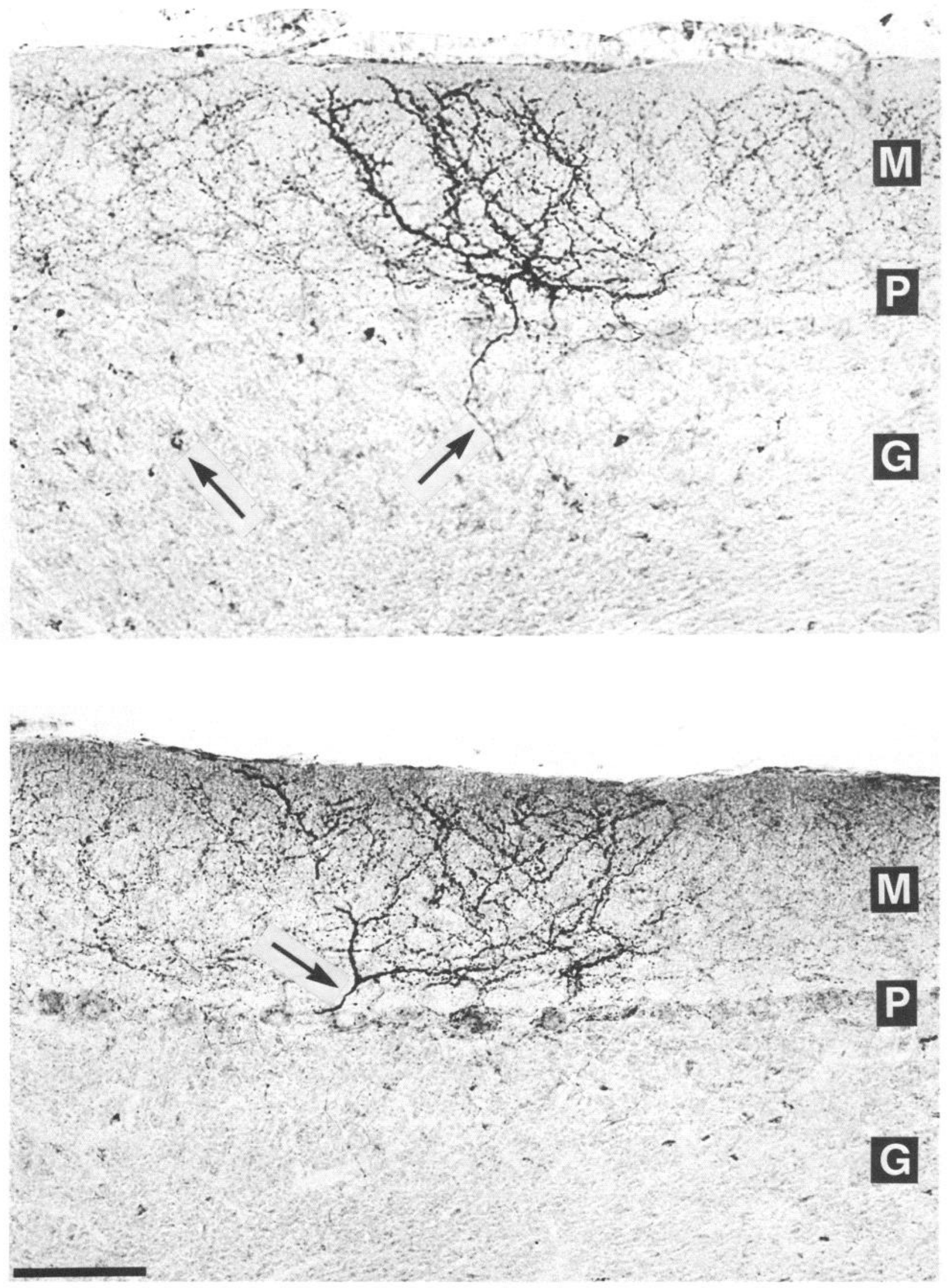

Figure 3. Immunoreactive axons in sagittal sections through cerebellar cortex. Note that the vast majority of immunoreactivity is confined to the molecular layer $(M)$. The arrow in the bottom panel indicates the bifurcation of one process at a point just superficial to the Purkinje cell layer $(P)$. Such bifurcations are characteristic of climbing fibers. Isolated fibers can be seen passing through the Purkinje cell layer. In the granular layer $(G)$, occasional fibers are evident (right arrow, top panel), as are structures resembling efflorescences (left arrow, top panel). Scale bar, $100 \mu \mathrm{m}$. 
Figure 4. Bright-field photomicrograph of labeled axons in a coronal section through the cerebellar cortex. The locations of the molecular $(M)$, Purkinje cell $(P)$, and granular $(G)$ layers are indicated. The arrows indicate labeled axons in the granular layer which form efflorescences. Note also the vertical (radial) orientation of paired, labeled axons in the molecular layer. Scale bar, $50 \mu \mathrm{m}$.

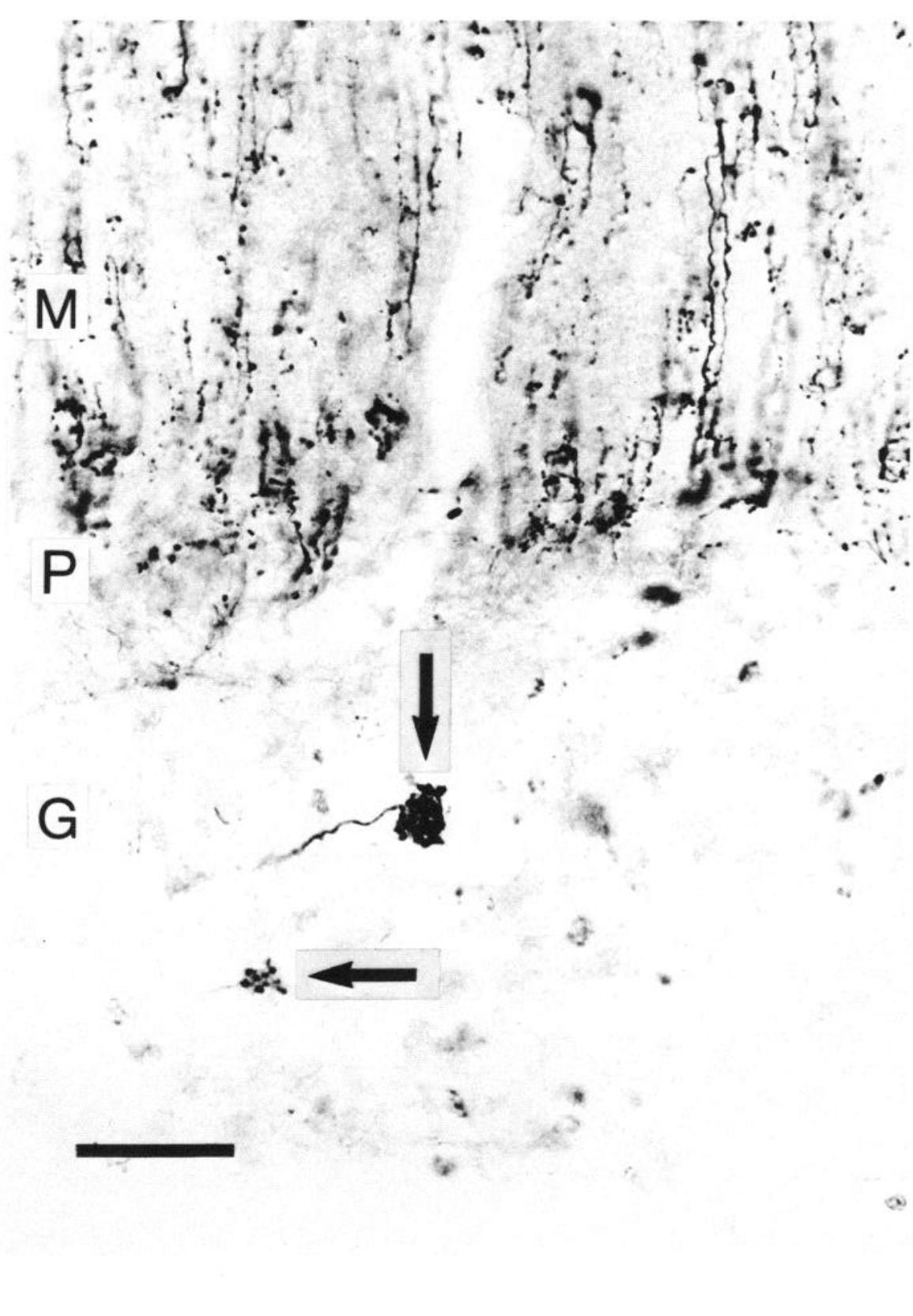

As indicated in Figure 12, the organization of densely labeled zones into parasagittal stripes was clear throughout the mediolateral extent of the vermis in frontal sections through both the anterior and posterior lobes. The stripes of dense labeling were of variable width within a given frontal section, and a given stripe varied in width along its rostral-caudal extent. As noted above, the uvula was densely innervated throughout, and the pyramis contained a large zone of densely labeled axons. In certain portions of the pyramis, stripes were also evident (Fig. 9). Usually, one additional stripe of dense staining was evident in the intermediate zone, the parasagittal organization of this stripe being clear only in the anterior lobe. In the intermediate zone of the posterior lobe, a circumscribed area of dense innervation was evident along the medial edge of the dorsal paraflocculus.

In the lateral hemispheres, immunoreactive axons in the molecular layer were usually sparsely distributed and only mod- 


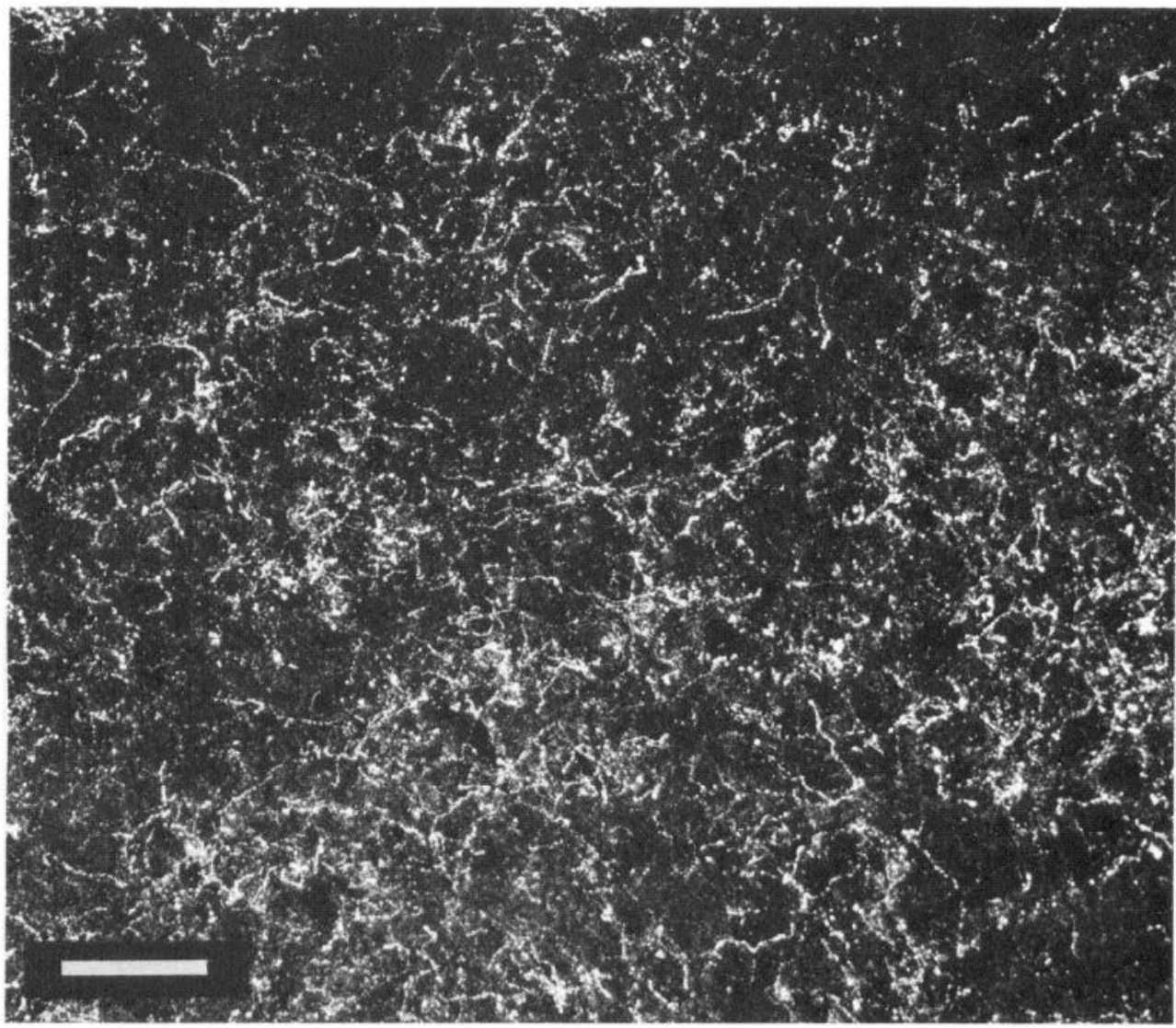

Figure 5. Dark-field photomicrograph of immunoreactive fibers in a coronal section through the fastigial nucleus. These fine-caliber fibers are highly arborized. Scale bar, $100 \mu \mathrm{m}$. erately or lightly labeled. A striking exception was the region of crus I just ventral to the posterior superior fissure. As indicated in Figure $12 C$, this area contained a dense collection of heavily labeled axons.

\section{Discussion}

\section{Summary of results and comparison with the olivocerebellar} climbing-fiber system

These results indicate that in these 2 monkey species CRF is contained within inferior olive perikarya and in their axons which constitute the climbing-fiber input to cerebellum. This is evident within the inferior olive as immunoreactivity within perikarya and axons. In the cerebellum, immunoreactivity is present in the molecular layer in axons with the same morphology as that previously reported for climbing fibers (Scheibel and Scheibel, 1954; Palay and Chan, 1974). In the sagittal plane, for example, individual axonal arbors originate from isolated, thick processes just superficial to the Purkinje cell layer and arborize over a wide area within the sagittal plane in a pattern similar to the arborization of climbing fibers. In coronal sections, radially oriented, parallel pairs of labeled axons are evident. Also, examination of the present material in several planes of section indicates that there is a large-diameter process that completely encapsulates the base of the Purkinje cell apical dendrite. Immunoreactive axons are also evident as efflorescences in the granular layer and as apparent terminal arbors in cerebellar nuclei. It has previously been reported that collaterals of climbing fibers project into both of these areas and exhibit the types of terminal morphology observed in the present study (Scheibel and Scheibel, 1954; Palay and Chan, 1974). Although morphology alone does not allow an unambiguous classification of the variety of labeled processes observed in the granular layer, at least a subset of them most likely comprises those formed by collaterals of climbing fibers.

In agreement with the observations of Cummings et al. (1988) in cat and sheep, 2 other populations of labeled axons were also evident. First, some of the labeled elements in the granular layer of monkey exhibit the morphological characteristics of mossy fiber axons, i.e., enlargements and rosette configurations. Second, fine, varicose fibers were often evident running within and adjacent to the Purkinje cell layer. As indicated by Cummings et al. (1988), these observations suggest that there are also extraolivary, CRF-containing afferents to cerebellar cortex. In any case, the present morphological observations strongly indicate that CRFLI is contained (although not exclusively) within the olivocerebellar pathway since processes exhibiting all known morphological features of climbing fibers and their collaterals are observed to contain CRFLI in these 2 species.

The interpretation that CRFLI is contained within the olivocerebellar system is also supported by the observation in the present study of a distinct regional and parasagittal organization of labeled molecular layer axons. The present observations indicate that CRF is contained in immunohistochemically detectable levels in all inferior olive neurons and their projections in these species. This is evidenced by the presence of clear immunoreactivity in all inferior olive perikarya examined in counterstained sections and by the fact that labeled axons are evident in all those regions of cerebellar cortex examined. However, the present observations also suggest that there are substantial differences in the intracellular levels of CRF in different 


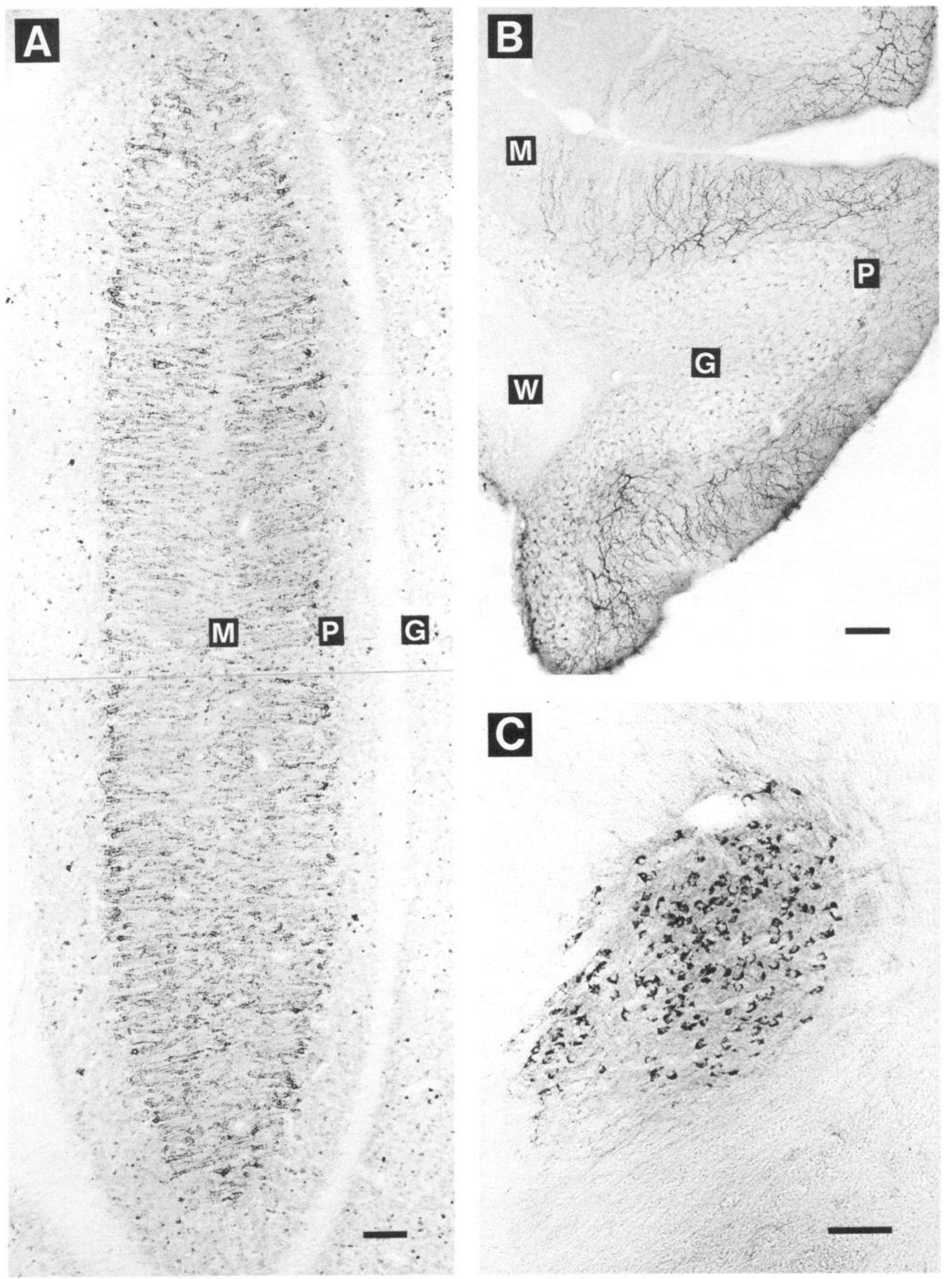




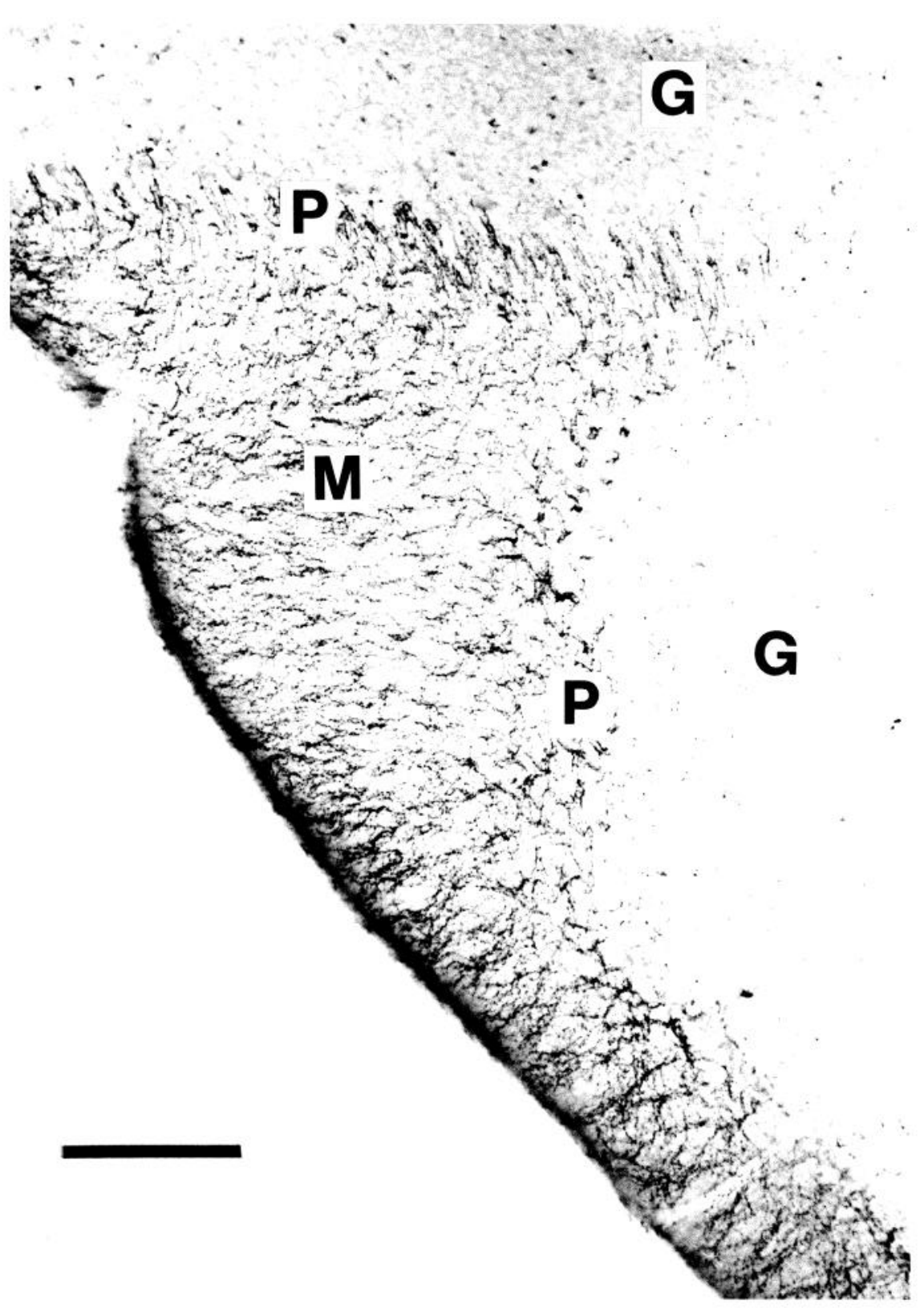

Figure 7. Bright-field photomicrograph of a coronal section through the paraflocculus. This region is very densely innervated. The characteristic distribution of axons in the molecular layer $(M)$ is evident. Large-caliber fibers can be seen in the Purkinje cell layer $(P)$, and occasional fibers and efflorescences are evident in the granular layer $(G)$. Scale bar, $200 \mu \mathrm{m}$. subdivisions of the olivocerebellar projection system. In these 2 monkey species, the perikarya of the medial accessory olive are more densely labeled than those of other olivary subdivisions. This is congruent with the presence of parasagittal zones of intensely labeled terminal axons in the vermis and portions of the intermediate zone, with the observation of areas of dense innervation in the pyramis and dorsal paraflocculus, and with the existence of a uniform, dense innervation of the uvula, since these terminal fields match the known projections of the medial accessory olive in these species (Brodal and Brodal, 1981, 1982;
Whitworth and Haines, 1986). In monkey, the medial accessory olive is known to project to parasagittal zones A and C2 (Brodal and Brodal, 1981, 1982), and these are presumably the zones exhibiting CRFLI stripes in the present study. Dense labeling of presumed climbing fibers was also observed in a limited portion of crus I. Although much of crus I receives its climbingfiber innervation from the principal olive, there is evidence that parts of this area are innervated by the medial accessory olive (Courville and Faraco-Cantin, 1980).

Several lines of evidence suggest that parasagittal zonation is

Figure 6. Bright-field photomicrographs of labeled axons in the uvula $(A)$ and pyramis $(B)$ regions of cerebellar cortex and labeled perikarya in nucleus beta of the inferior olive $(C)$. The section through the uvula $(A)$ is in the coronal plane, while that through the pyramis is in the sagittal plane, creating the obvious difference in the appearance of the axons. The photograph of the uvula has been rotated by $90^{\circ}$, and the labels are positioned on the midline. These sections illustrate the high density of intensely labeled axons in the molecular layer in these subdivisions of the cerebellar cortex. $C$ illustrates the dense labeling of perikarya in nucleus beta, a component of the medial accessory olive. Nucleus beta is the sole source of climbing fibers for the uvula, while the pyramis receives such innervation from nucleus beta, as well as other subdivisions of the medial accessory olive (Brodal and Brodal, 1981, 1982). Scale bars, $100 \mu \mathrm{m}$. $M$, molecular layer; $P$, Purkinje cell layer; $G$, granular layer; $W$, white matter. 
Figure 8. Dark-field photomontage of labeled axons in a coronal section through several folia of the cerebellar cortex in the vermis of the anterior lobe. Each Purkinje cell layer $(P)$ is labeled, and the arrows indicate the position and orientation of the midline. Within each folium, labeled axons are largely confined to the molecular layer, and dense patches of intensely labeled axons alternate with areas in which the density of labeled axons is much lower. Across folia, the regions containing labeled axons are aligned in the parasagittal plane, forming longitudinal stripes. Scale bar, $200 \mu \mathrm{m}$.

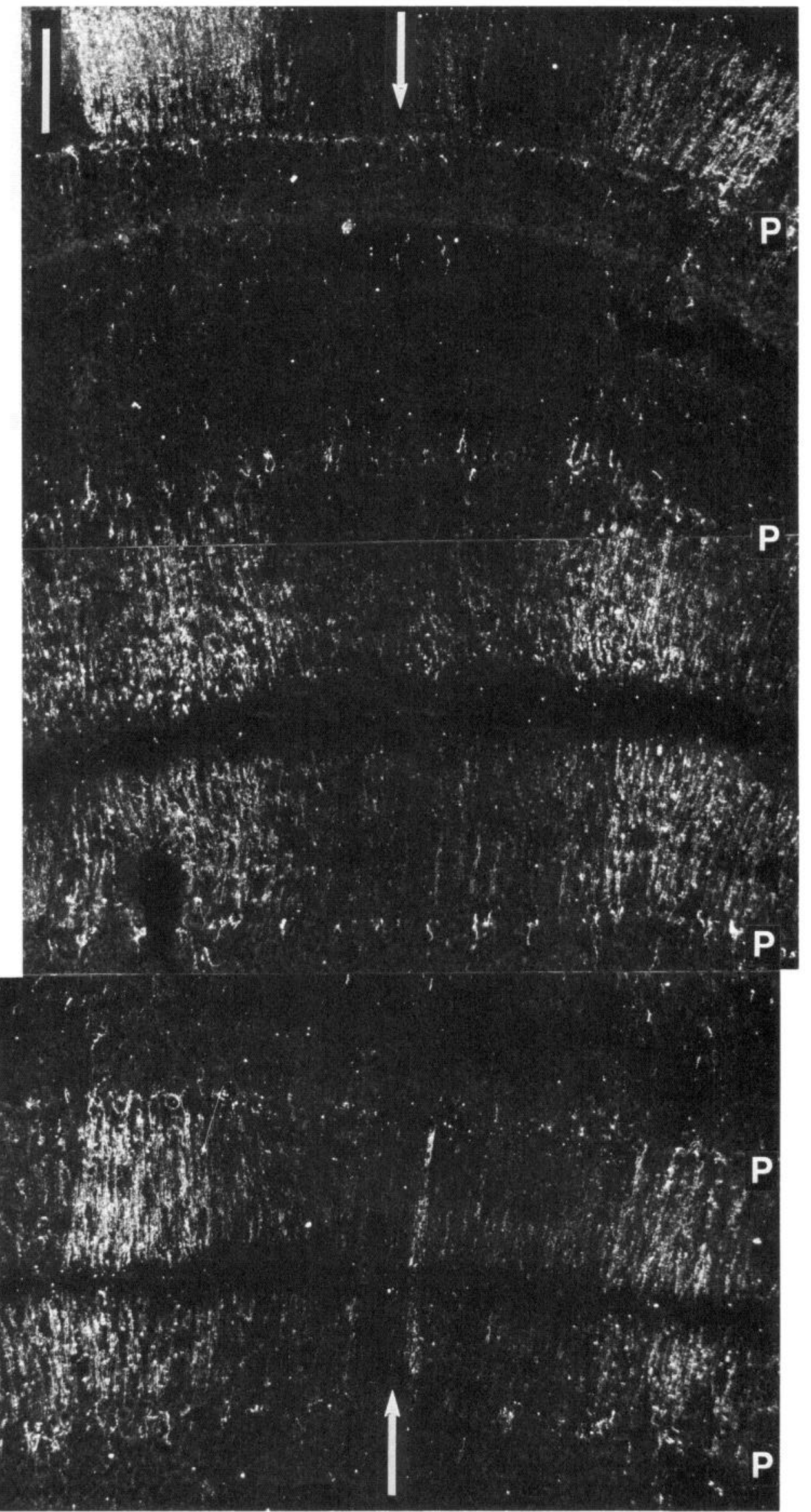




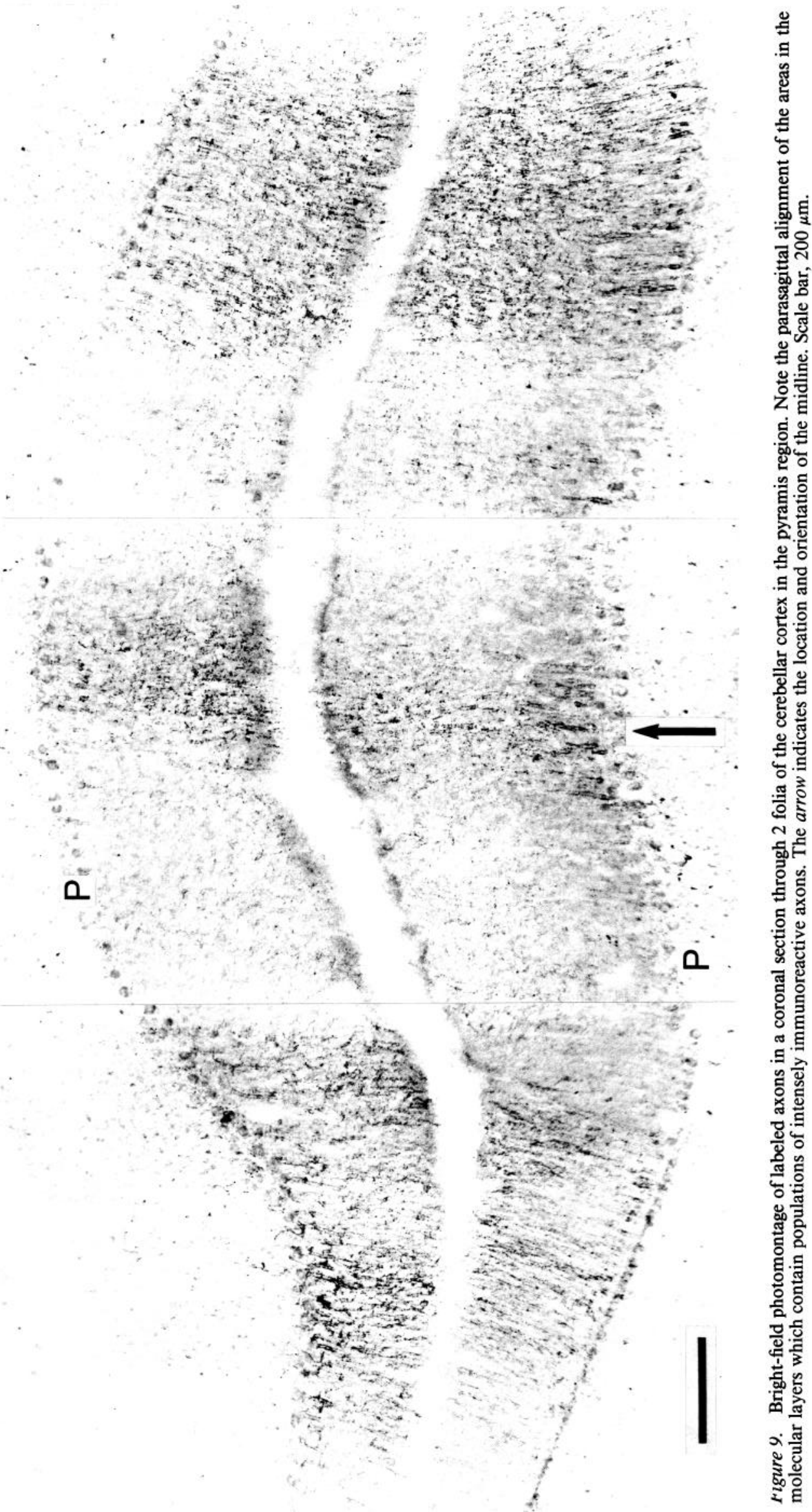




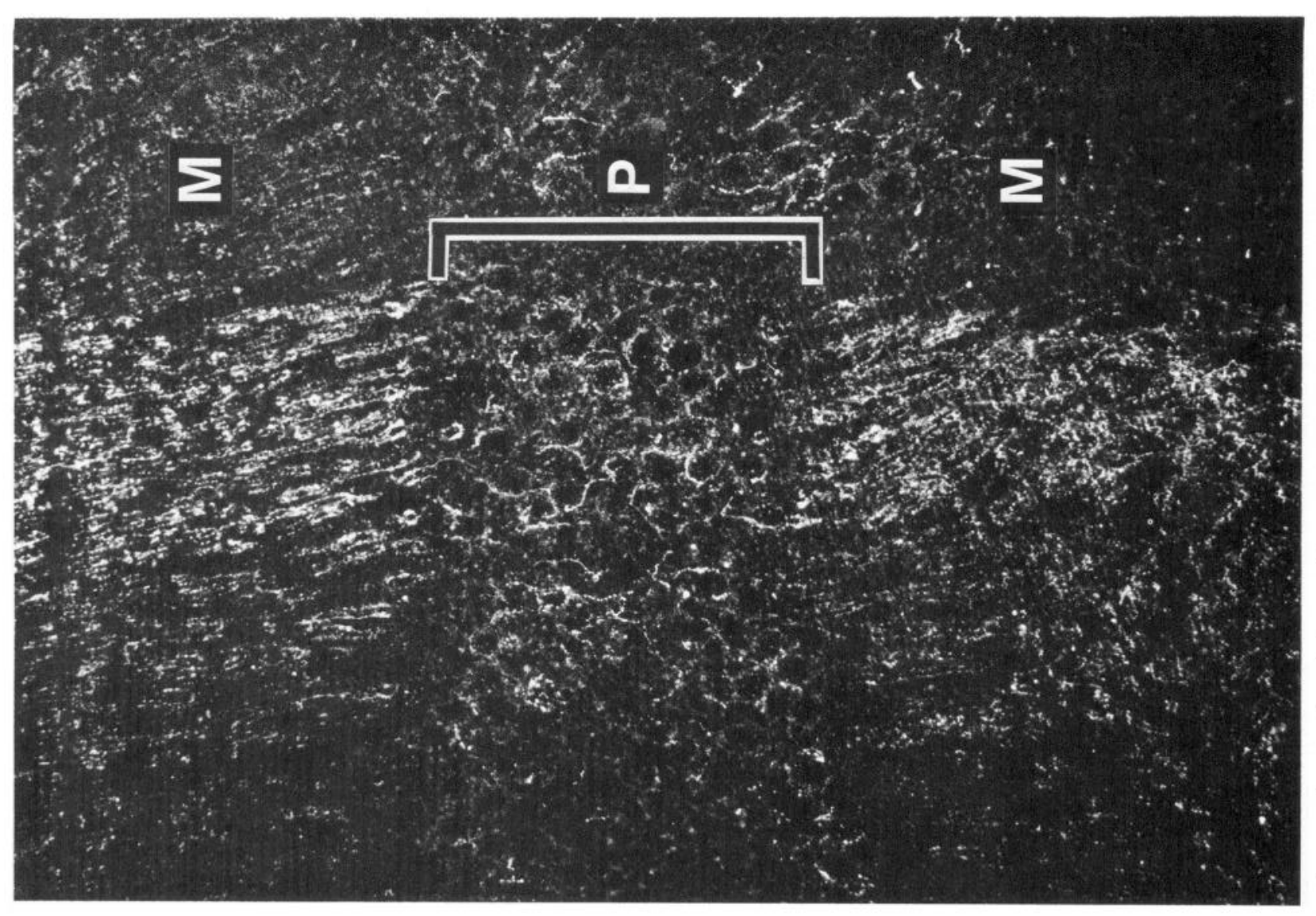

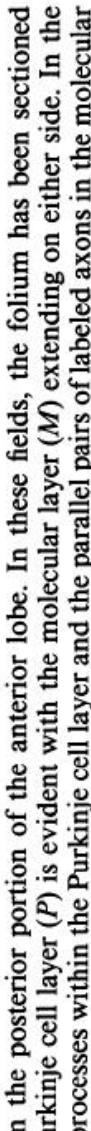

총를

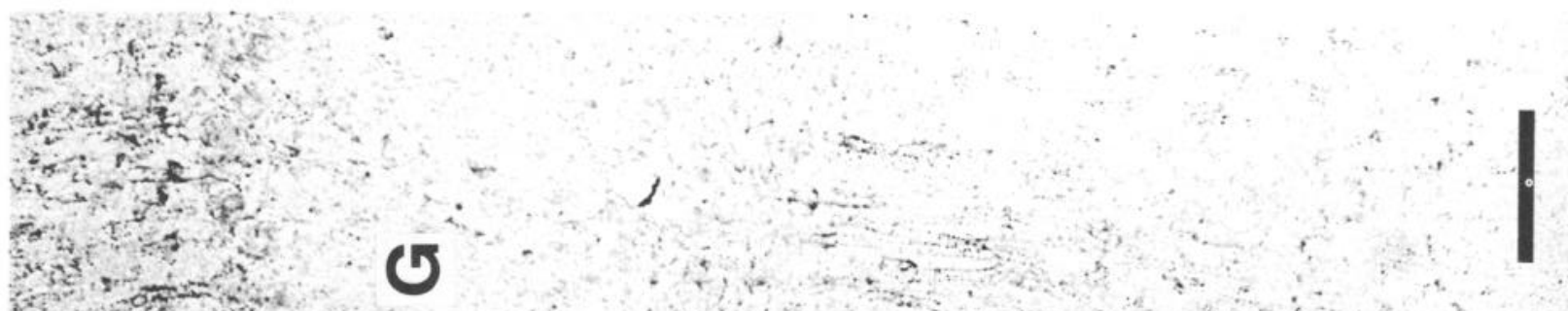

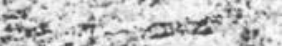

空

.

泣

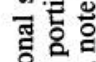

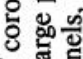

诺

눙

洁是

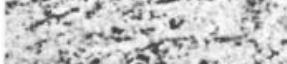

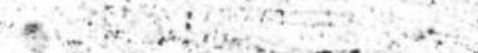

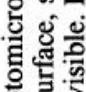

tom tor in

and $x^{2}+x^{4}$

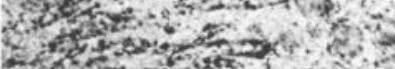

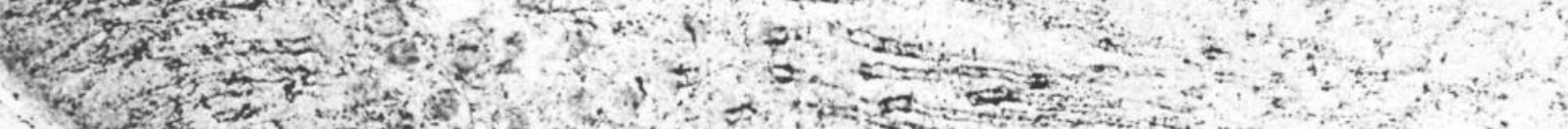

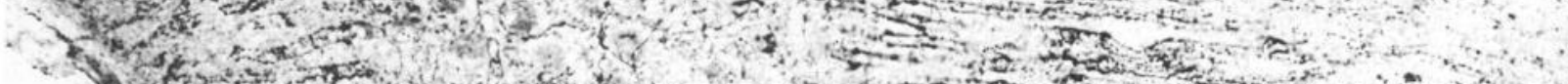

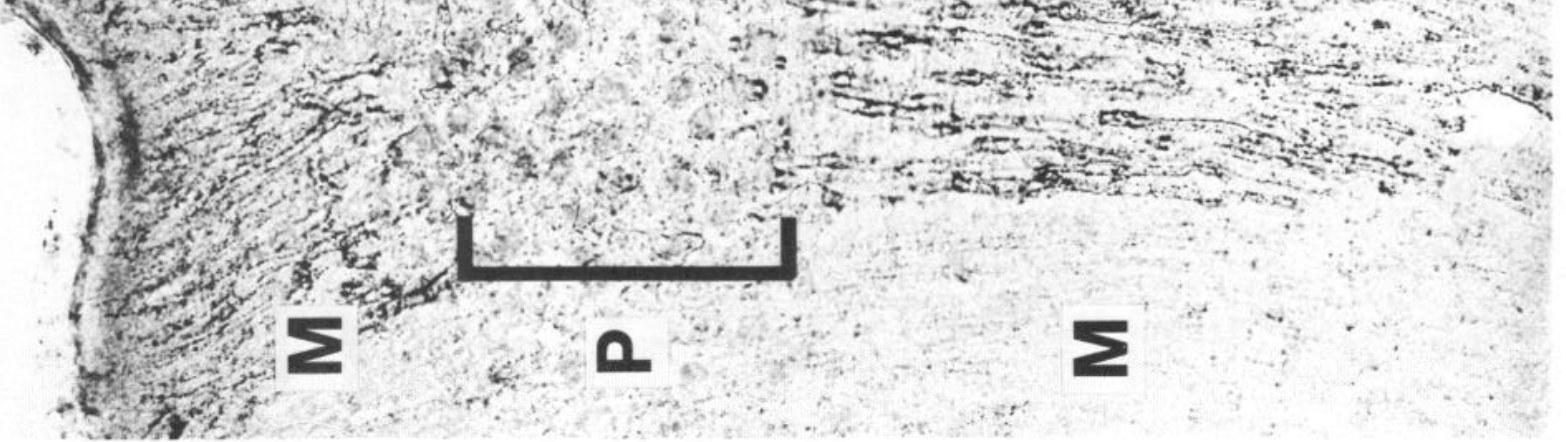

을

a

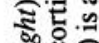

ज० क्ष

긍

政

尊需

몽

胥胥

꿍 웅.몰

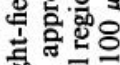

象.

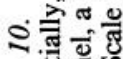

o 층

迢志氞 


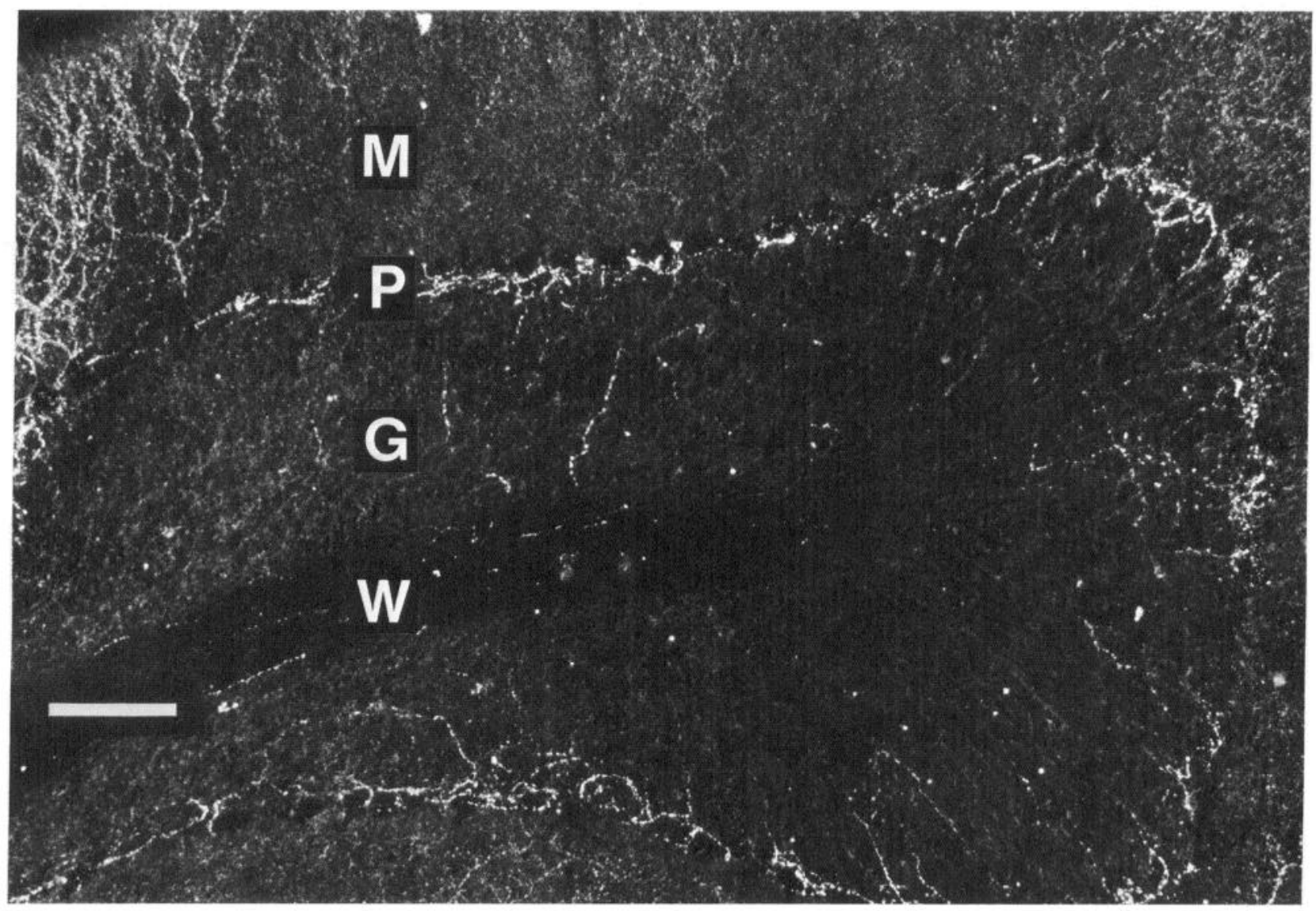

Figure 11. Dark-field photomicrograph of a sagittal section through the vermis. Note that some areas of the molecular layer $(M)$ contain dense immunoreactive axons while others do not. However, intensely immunoreactive axons are evident in the Purkinje cell layer $(P)$ even in those regions in which such axons are not evident in the molecular layer. Occasional labeled axons are evident in the granular layer $(G)$ and in the white matter $(W)$. Scale bar, $100 \mu \mathrm{m}$.

an essential element of cerebellar cortical organization. In addition to the previous demonstrations of parasagittal zonation of olivocerebellar afferents in monkey, there have been similar demonstrations in cat (Groenewegen and Voogd, 1977; Groenewegen et al., 1979) and rat (Campbell and Armstrong, 1983a, b; see also Brodal and Kawamura, 1980, for review). Previous studies have also provided immunohistochemical evidence for parasagittal zonation of antigens intrinsic to Purkinje cells (ChanPalay et al., 1981, 1982; Hawkes and Leclerc, 1987). It is not clear how the parasagittal zones defined by CRFLI are spatially or functionally related to the zones defined by other methods.

\section{Comparison of present results and previous evidence localizing $C R F$ in the olivocerebellar system}

Previous observations, summarized at the beginning of this report, have suggested that CRF is contained within the olivocerebellar pathway of rat, cat, sheep, and human. Both immunohistochemical and in situ hybridization techniques have yielded data compatible with this hypothesis. For example, CRFLI has been observed in inferior olive perikarya of rat (Palkovits et al., 1987; Sakanaka et al., 1987), cat (Cummings et al., 1988; Kitahama et al., 1988), and sheep (Cummings et al., 1988). In rodent studies, it has generally been observed that unambiguous staining of neuronal perikarya for CRF, except in the paraventricular nucleus, is obtained only when colchicine has been administered prior to sacrifice. Colchicine was not utilized in the present studies because of the difficulties of determining effective, nonlethal doses in these primate species. Despite the lack of colchicine treatment, unambiguously reactive cell bodies were observed in the inferior olive. The present observations and those of CRF immunoreactivity in human inferior olive neurons (Powers et al., 1987) may indicate that CRF is present in higher concentrations in these neurons in primates than in rat.

This interpretation is reinforced by our observation (data not presented) that with the antiserum and immunohistochemical methods used in the present study, we observe few immunoreactive olivary neurons in rats not previously treated with colchicine. The utilization of in situ hybridization methods has revealed CRF-mRNA in rat, baboon, and human inferior olivary neurons (Young et al., 1986; Palkovits et al., 1987). Knife cuts through the olivocerebellar pathway have been shown to produce an accumulation of CRF immunoreactivity proximal to such cuts, indicating that $\mathrm{CRF}$ is indeed transported along this pathway (Palkovits et al., 1987). Previous immunohistochemical studies have observed axons exhibiting CRFLI in cerebellar cortex of rat (Merchenthaler, 1984; Palkovits et al., 1987; Sakanaka et al., 1987), cat (Cummings et al., 1988; Kitahama et al., 1988), sheep (Cummings et al., 1988), and human (Powers et al., 1987). Also, there have been recent reports of high levels of CRF receptors in rat (De Souza et al., 1985; De Souza, 1987), monkey (Millan et al., 1986), and human (Powers et al., 1987) 
A

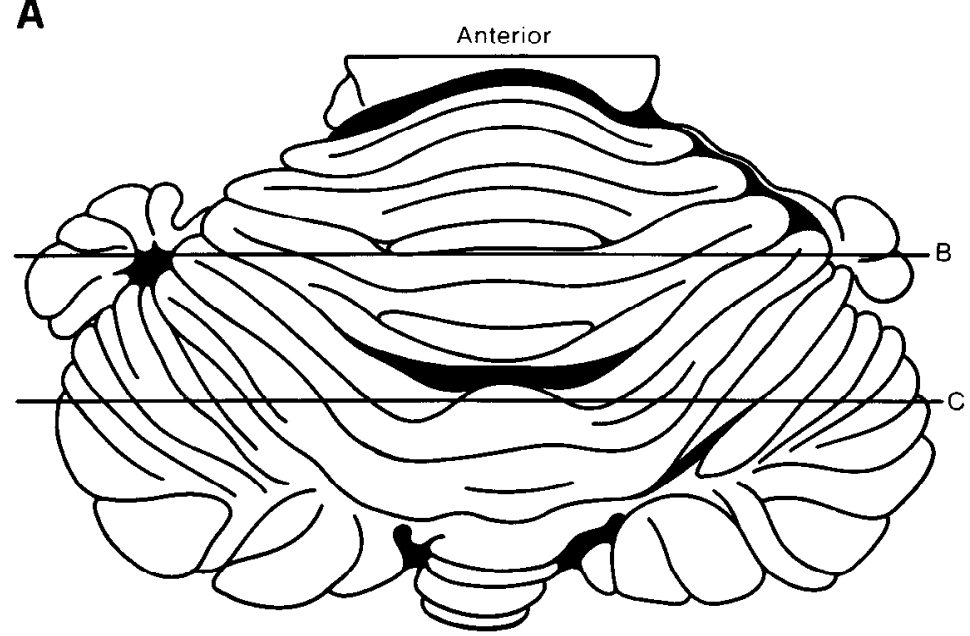

B

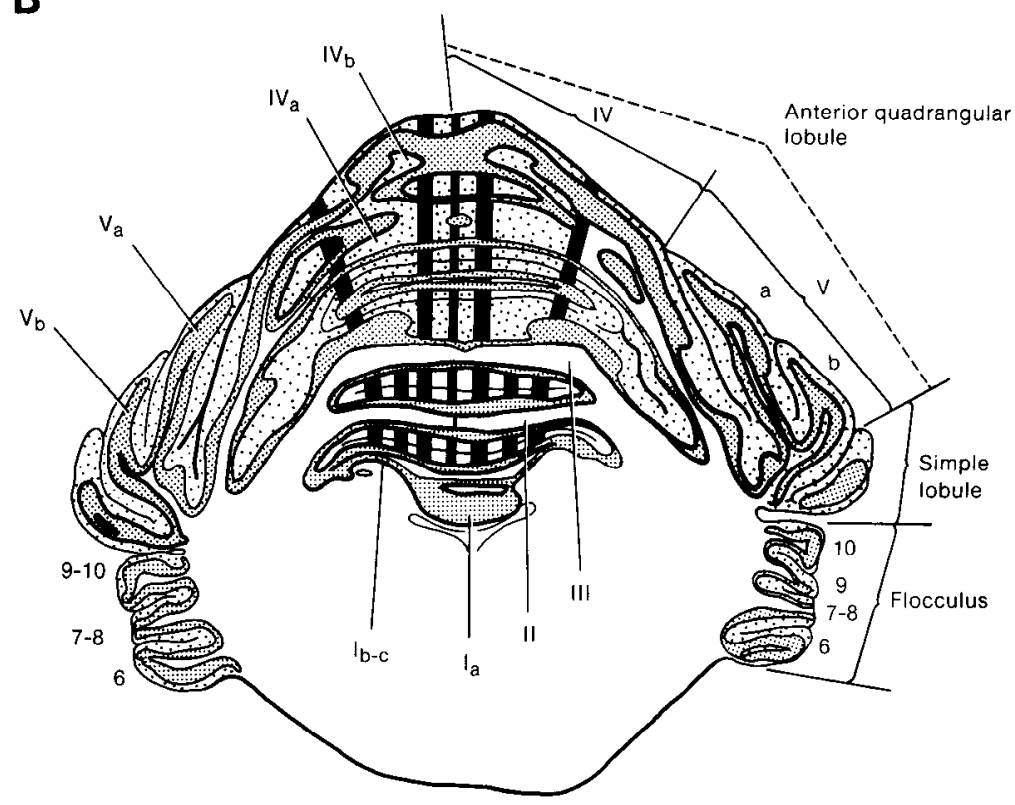

C

Figure 12. Schematic diagrams indicating the locations of parasagittal zones defined by dense collections of immunoreactive axons. $A$, Horizontal view of the dorsal surface of Saimiri cerebellum. The superimposed straight lines indicate the levels of the 2 coronal sections depicted in $B$ and $C$. In $B$ and $C$, black areas indicate zones in which a high density of labeled axons was evident in the molecular layer of each folium. The sparse stipple indicates the remaining molecular layer with its moderate density of labeled axons. The dense stipple indicates the location of the granular layer, and unshaded areas indicate the location of white matter.

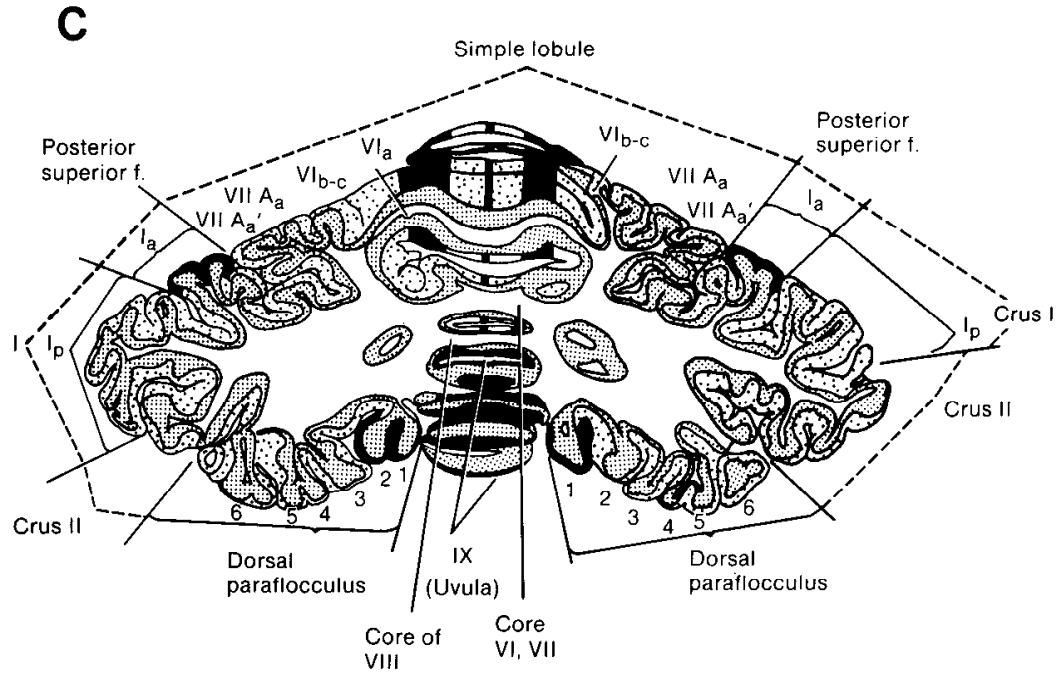


cerebellum. At the ultrastructural level, CRFLI terminals have been shown to establish synaptic contacts with dendritic spines of rat Purkinje cells (Palkovits et al., 1987).

The present observations reinforce and extend these previous observations in several ways. As in humans (Powers et al., 1987), CRFLI was demonstrated in inferior olive perikarya without colchicine pretreatment or lesions. However, the present report describes a distribution of CRFLI in olivary subdivisions that is different from those previously reported. Palkovits et al. (1987) reported denser staining in the principal olive, but none of the other previous studies in rat reported CRFLI in inferior olivary neurons or a preferential distribution of labeled cells. In the only report describing CRFLI in human inferior olivary neurons (Powers et al., 1987) and in one report of such immunoreactivity in cats (Kitahama et al., 1988), no preferential distribution was noted, while in another study (Cummings et al., 1988) of cat inferior olive, a different distribution than that described here was reported. In addition, the very intense labeling of cerebellar axons in the present study permitted a more detailed characterization of their morphology than has previously been reported for a primate species. This includes the description in the present study of the morphology of these axons in the molecular layer as observed in various planes of section. These observations document a strong resemblance to climbing fibers for the largest population of axons. Also, the present study has identified CRFLI within climbing-fiber-like efflorescences in the granular layer of cerebellar cortex and in axons in cerebellar nuclei, providing further evidence that CRFLI is present in olivocerebellar axons. Finally, the present report describes a clear regional and parasagittal organization of these axons in cerebellar cortex that has not been previously reported and documents a relationship between the preferential distribution of CRFLI in inferior olive and cerebellum that is compatible with the known relationships between olivary subdivisions and their cortical projections. Previous studies in rat describe a uniform distribution of CRFLI axons in cerebellar cortex, suggesting that there is a difference between rat and monkey in this regard. The only description of these axons in human cerebellum did not include a description of any regional or parasagittal organization, although labeled fibers were observed in the vermis (Powers et al., 1987). Thus, further studies will be necessary to determine whether CRFLI axons in human cerebellum display the morphological characteristics and distribution patterns observed in these 2 monkey species.

There have been previous reports of other peptides being contained within cerebellar afferents, e.g., enkephalin (Schulman et al., 1981; King et al., 1986) and substance P (Korte et al., 1980). It is possible that some of the immunoreactivity in the present study was due to the antiserum cross-reacting with these or some other peptide. Certain observations indicate that the probability of such cross-reactivity is limited: (1) as indicated in Materials and Methods, serum that had been preadsorbed with CRF did not produce any of the labeling described here, and (2) the CRFLI labeling obscrved in ccrcbcllum and other brain sites with this antiserum (see also, Foote et al., 1987; Foote and Cha, 1988) did not exhibit any systematic correspondence to the distributions of other known peptides.

\section{Functional implications}

The present observations reinforce many previous reports indicating that CRF is localized in extrahypophyseal circuits, where it may serve as a neurotransmitter (see Vale et al., 1983; Emeric-
Sauval, 1986, for reviews). There is also evidence that aspartate and/or glutamate may be a neurotransmitter in the olivocerebellar pathway (Wiklund et al., 1982, 1984; Toggenburger et al., 1983; Matute et al., 1987). Thus, it is possible that CRF is a cotransmitter with one of these substances in the olivocerebellar pathway, with the peptide playing a relatively greater role in those projections that originate in the medial accessory olive. There have been numerous speculations (see Ito, 1986, for a recent example) about the role of climbing-fiber input in the overall functioning of cerebellar cortex, but for the present the functional physiological effects of this pathway remain unclear, as do the possible contributions of CRF to these actions.

Several lines of evidence suggest that CRF-containing circuits in many brain regions may serve to coordinate the centrally mediatcd autonomic and bchavioral aspccts of stress responses (see Valentino and Foote, 1986, for review). In this regard, it is of interest that CRF within the cerebellum is concentrated in the vermis and the associated fastigial nucleus, areas previously implicated in arousal and autonomic and affective functions (e.g., Dempesy et al., 1983; Haines et al., 1984; Albert et al., 1985; Arneric et al., 1987). Thus, these cerebellar circuits may constitute one component of a larger CRF-containing network that becomes activated in response to stress-inducing stimuli.

\section{References}

Albert, T. J., C. W. Dempesy, and C. A. Sorenson (1985) Anterior cerebellar vermal stimulation: Effect on behavior and basal forebrain neurochemistry in rat. Biol. Psychiatry 20: 1267-1276.

Arneric, S. P., C. Iadecola, M. D. Underwood, and D. J. Reis (1987) Local cholinergic mechanisms participate in the increase in cortical cerebral blood flow elicited by electrical stimulation of the fastigial nucleus in rat. Brain Res. 411: 212-225.

Bloom, F. E., E. L. F. Battenberg, J. Rivier, and W. Vale (1982) Corticotropin releasing factor (CRF): Immunoreactive neurones and fibers in rat hypothalamus. Regulat. Peptides 4: 43-48.

Brodal, P., and A. Brodal (1981) The olivocerebellar projection in the monkey. Experimental studies with the method of retrograde tracing of horseradish peroxidase. J. Comp. Neurol. 201: 375-393.

Brodal P., and A. Brodal. (1982) Further observations on the olivocerebellar projection in the monkey. Exp. Brain Res. 45: 71-83.

Brodal, A., and K. Kawamura (1980) Olivocerebellar projection: A review. Adv. Anat. Embryol. Cell Biol. 64: 1-140.

Campbell, N. C., and D. M. Armstrong (1983a) The olivocerebellar projection in the rat: An autoradiographic study. Brain Res. 275:215233.

Campbell, N. C., and D. M. Armstrong (1983b) Topographical localization in the olivocerebellar projection in the rat: An autoradiographic study. Brain Res. 275: 235-249.

Cha, C. I., and S. L. Foote (1987) Corticotropin-releasing factor-like immunoreactivity (CRFLI) in inferior olive perikarya and in climbing fiber-like profiles in cerebellar cortex of monkey. Soc. Neurosci. Abstr. 13: 1262 .

Chan-Palay, V., G. Nilaver, S. L. Palay, M. C. Beinfeld, E. A. Zimmerman, J.-Y. Wu, and T. L. O'Donohue (1981) Chemical heterogeneity in cerebellar purkinje cells: Existence and co-existence of glutamic acid decarboxylase-like and motilin-like immunoreactivities. Proc. Natl. Acad. Sci. USA 78: 7787-7791.

Chan-Palay, V., S. L. Palay, and J.-Y. Wu (1982) Sagittal cerebellar microbands of taurine neurons: Immunocytochemical demonstration by using antibodies against the taurine synthesizing enzyme cysteine sulfinic acid decarboxylase. Proc. Natl. Acad. Sci. USA 79: 42214225 .

Courville, J., and F. Faraco-Cantin (1980) Topography of the olivocerebellar projection: An experimental study in the cat with an autoradiographic tracing method. In The Inferior Olivary Nucleus: Anatomy and Physiology, J. Courville et al., eds., pp. 235-277, Raven, New York.

Cummings, S., B. Sharp, and R. Elde (1988) Corticotropin-releasing factor in cerebellar afferent systems: A combined immunohistochemistry and retrograde transport study. J. Neurosci. 8: 543-554. 
Cummings, S., R. Elde, J. Ells, and A. Lindall (1983) Corticotropinreleasing factor immunoreactivity is widely distributed within the central nervous system of the rat: An immunohistochemical study. J. Neurosci. 3: 1355-1368.

Dempesy, C. W., D. M. Tootle, C. J. Fontana, A. T. Fitzjarrell, R. E. Garey, and R. G. Heath (1983) Stimulation of the paleocerebellar cortex of the cat: Increased rate of synthesis and release of catecholamines at limbic sites. Biol. Psychiatry 18: 127-132.

De Souza, E. B. (1987) Corticotropin-releasing factor receptors in the rat central nervous system: Characterization and regional distribution. J. Neurosci. 7: 88-100.

De Souza, E. B., T. R. Insel, M. H. Perrin, J. Rivier, W. W. Vale, and M. J. Kuhar (1985) Corticotropin-releasing receptors are widely distributed within the rat central nervous system: An autoradiographic study. J. Neurosci. 5: 3189-3203.

Emeric-Sauval, E. (1986) Corticotropin-releasing factor (CRF)-A review. Psychoneuroendocrinology 11: 277-294.

Emmers, R., and K. Akert (1963) A Stereotaxic Atlas of the Brain of the Squirrel Monkey(Saimiri sciureus), University of Wisconsin Press, Madison.

Fellman, D., C. Bugnon, J. L. Bresson, A. Gouget, J. Cardot, M. C. Clavequin, and M. Hadjiyiassemis (1984) The CRF neuron: Immunocytochemical study. Peptides (Suppl. 1) 5: 19-33.

Foote, S. L., and C. I. Cha (1988) Distribution of corticotropin-releasing factor-like immunoreactivity in brainstem of two monkey species (Saimiri sciureus and Macaca fascicularis): An immunohistochemical study. J. Comp. Neurol. (in press).

Foote, S. L., C. I. Cha, D. A. Lewis, and J. H. Morrison (1987) An immunohistochemical study of corticotropin-releasing factor-like immunoreactivity (CRFLI) in monkey brain. Soc. Neurosci. Abstr. 13: 1384.

Groenewegen, H. J., and J. Voogd (1977) The parasagittal zonation within the olivocerebellar projection. J. Comp. Neurol. 174: 417488.

Groenewegen, H. J., J. Voogd, and S. L. Freedman (1979) The parasagittal zonation within the olivocerebellar projection. J. Comp. Neurol. 183: 551-602.

Haines, D. E., E. Dietrichs, and T. E. Sowa (1984) Hypothalamocerebellar and cerebello-hypothalamic pathways: A review and hypothesis concerning cerebellar circuits which may influence autonomic centers and affective behavior. Brain Behav. Evol. 24: 198220.

Hawkes, R., and N. Leclerc (1987) Antigenic map of the rat cerebellar cortex: The distribution of parasagittal bands as revealed by monoclonal anti-Purkinje cell antibody mabQ113. J. Comp. Neurol. 256: $29-41$.

Ito, M. (1986) Long-term depression as a memory process in the cerebellum. Neurosci. Res. 3: 531-539.

Joseph, S., and K. M. Knigge (1983) Corticotropin releasing factor: Immunocytochemical localization in rat brain. Neurosci. Lett. 35: 135-141.

Kawata, M., K. Hashimoto, J. Takahara, and Y. Sano (1982) Immunohistochemical demonstration of the localization of corticotropin releasing factor-containing neurons in the hypothalamus of mammals including primates. Anat. Embryol. 165: 303-313.

Kawata, M., K. Hashimoto, J. Takahara, and Y. Sano (1983) CRFimmunoreactive nerve fibers in the circumventricular organs of the monkey, Macaca fuscata. Cell Tissue Res. 232: 679-683.

King, J. S., R. Ho, and G. Bishop (1986) Anatomical evidence for enkephalin immunoreactive climbing fibers in the opossum's cerebellar cortex. J. Neurocytol. 15: 545-559.

Kitahama, K., P.-H. Luppi, G. Tramu, J.-P. Sastre, C. Buda, and M. Jouvet (1988) Localization of CRF-immunoreactive neurons in the cat medulla oblongata: Their presence in the inferior olive. Cell Tissue Res. 251: 137-143.

Korte, G., E. Rcincr, and H. Karten (1980) Substance P-like immunoreactivity in cerebellar mossy fibers and terminals in the red-eared turtle Chrysemys scripta elegans. Neuroscience 5: 903-914.

Kusama, T., and M. Mabuchi (1970) Stereotaxic Atlas of the Brain of Macaca fuscata, University of Tokyo Press/University Park Press, Tokyo.

Madigan, J. C., Jr., and M. B. Carpenter (1971) Cerebellum of the Rhesus Monkey, University Park Press, Baltimore.

Matute, C., L. Wiklund, P. Streit, and M. Cuenod (1987) Selective retrograde labeling with $\mathrm{d}-\left[{ }^{3} \mathrm{H}\right]$-aspartate in the monkey olivocerebellar projection. Exp. Brain Res. 66: 445-447.
Merchenthaler, I. (1984) Corticotropin releasing factor (CRF)-like immunoreactivity in the rat central nervous system. Extrahypothalamic distribution. Peptides (Suppl.) 5: 53-69.

Merchenthaler, I., S. Vigh, P. Petrusz, and A. V. Schally (1982) Immunocytochemical localization of corticotropin-releasing factor (CRF) in the rat brain. Am. J. Anat. 165: 385-396.

Merchenthaler, I., S. Vigh, A. V. Schally, W. E. Stumpf, and A. Arimura (1984) Immunocytochemical localization of corticotropin releasing factor (CRF)-like immunoreactivity in the thalamus of the rat. Brain Res. 323: 119-122.

Millan, M. A., D. M. Jacobowitz, R. L. Hauger, K. J. Catt, and G. Aguilera (1986) Distribution of corticotropin-releasing factor receptors in primate brain. Proc. Natl. Acad. Sci. USA 83: 1921-1925.

Morrison, J. H., and S. L. Foote (1986) Noradrenergic and serotonergic innervation of cortical and thalamic visual structures in old and new world monkeys. J. Comp. Neurol. 243: 117-138.

Olschowka, J. A., T. L. O'Donohue, G. P. Mueller, and D. M. Jacobowitz (1982) Hypothalamic and extrahypothalamic distribution of CRF-like immunoreactive neurons in the rat brain. Neuroendocrinology 35: 305-308.

Palay, S. L., and V. Chan (1974) Cerebellar Cortex, Springcr-Vcrlag, New York.

Palkovits, M., M. J. Brownstein, and W. Vale (1983) Corticotropinreleasing factor (CRF) immunoreactivity in hypothalamic and extrahypothalamic nuclei of sheep brain. Neuroendocrinology 37: 302305.

Palkovits, M., M. J. Brownstein, and W. Vale (1985) Distribution of corticotropin-releasing factor in rat brain. Fed. Proc. Fed. Am. Soc. Exp. Biol. 44: 215-219.

Palkovits, M., C. Leranth, T. Gorcs, and W. S. Young III (1987) Corticotropin-releasing factor in the olivocerebellar tract of rats: Demonstration by light- and electron-microscopic immunohistochemistry and in situ hybridization histochemistry. Proc. Natl. Acad. Sci. USA 84: 3911-3915.

Paull, W. K., C. F. Phelix, M. Copeland, P. Palmiter, F. P. Gibbs, and C. Middleton (1984) Immunohistochemical localization of corticotropin-releasing factor (CRF) in the hypothalamus of the squirrel monkey, Saimiri sciureus. Peptides (Suppl. 1) 5: 45-51.

Powers, R. E., E. B. De Souza, L. C. Walker, D. L. Price, W. W. Vale, and W. S. Young III (1987) Corticotropin-releasing factor as a transmitter in the human olivocerebellar pathway. Brain Res. 415: 347352.

Rivier, J., J. Spiess, and W. Vale (1983) Characterization of rat hypothalamic corticotropin-releasing factor. Proc. Natl. Acad. Sci. USA $80 ; 4851-4855$.

Sakanaka, M., T. Shibasaki, and K. Lederis (1987) Corticotropin releasing factor-like immunoreactivity in the rat brain as revealed by a modified cobalt-glucose oxidase-diaminobenzidine method. J. Comp. Neurol. 260: 256-298.

Scheibel, M. E., and A. B. Scheibel (1954) Observations on the intracortical relations of the climbing fibers of the cerebellum. Golgi study. J. Comp. Neurol. 101: 733-764.

Schipper, J., J. W. M. Steinbusch, I. Vermes, and F. J. H. Tilders (1983) Mapping of CRF-immunoreactive nerve fibers in the medulla oblongata and spinal cord of the rat. Brain Res. 267: 145-150.

Schulman, J., T. Finger, N. Brecha, and H. Karten (1981) Enkephalin immunoreactivity in Golgi cells and mossy fibres of mammalian, avian, amphibian and teleost cerebellum. Neuroscience 6: 2407-2416.

Shibihara, S., Y. Morimoto, Y. Furutani, M. Notaki, H. Takahashi, S. Shimizu, S. Horikawa, and S. Numa (1983) Isolation and sequence analysis of the human corticotropin-releasing factor precursor gene. EMBO J. 2: 775-779.

Skofitsch, G., and D. M. Jacobowitz (19.85) Distribution of corticotropin releasing factor-like immunoreactivity in the rat brain by immunohistochemistry and radioimmunoassay: Comparison and characterization of ovine and rat/human CRF antisera. Peptides 6:319336.

Swanson, L. W., P. E. Sawchenko, J. Rivier, and W. W. Vale (1983) Organization of ovine corticotropin-releasing factor immunoreactive cells and fibers in the rat brain: An immunohistochemical study. Neuroendocrinology 36: 165-186.

Toggenburger, G., L. Wiklund, H. Henke, and M. Cuenod (1983) Release of endogenous and accumulated exogenous amino acids from slices of normal and climbing fiber-deprived rat cerebellar slices. J. Neurochem. 41: 1606-1613.

Vale, W., J. Spiess, C. Rivier, and J. Rivier (1981) Characterization 
of a 41-residue ovine hypothalamic peptide that stimulates secretion of corticotropin and beta-endorphin. Science 213: 1394-1397.

Vale, W., C. Rivier, M. R. Brown, J. Spiess, G. Koob, L. Swanson, L. Bilezikjian, F. Bloom, and J. Rivier (1983) Chemical and biological characterization of corticotropin-releasing factor. Rec. Prog. Horm. Res. 39: 245-269.

Valentino, R. J., and S. L. Foote (1986) Brain noradrenergic neurons, corticotropin-releasing factor, and stress. In Neural and Endocrine Peptides and Receptors, T. Moody, ed., pp. 101-120. Plenum, New York.

Whitworth, R. H., Jr., and D. E. Haines (1986) The inferior olive of Saimiri sciureus: Olivocerebellar projections to the anterior lobe. Brain Res. 372: 55-71.
Wiklund, L., G. Toggenburger, and M. Cuenod (1982) Aspartate: Possible neurotransmitter in cerebellar climbing fibers. Science $216: 78-$ 79.

Wiklund, L., G. Toggenburger, and M. Cuenod (1984) Selective retrograde labelling of the rat olivocerebellar climbing fiber system with D- $\left[{ }^{3} \mathrm{H}\right]$-aspartate. Neuroscience $13: 441-468$.

Young, W. S., III, L. C. Walker, R. E. Powers, E. B. De Souza, and D. L. Price (1986) Corticotropin-releasing factor mRNA is expressed in the inferior olives of rodents and primates. Mol. Brain Res. 1: 189192. 